\title{
infâncias, cidade e relações intergeracionais na vida cotidiana
}

\author{
maria tereza goudard tavares ${ }^{1}$ \\ universidade do estado do rio de janeiro, brasil \\ orcid id: http:/ / orcid.org/0000-0002-9856-5098
}

resumo

O presente artigo deriva de minha participação no II Congresso de Estudos da infância: Politizações e Estesias, realizado em setembro de 2019, na UERJ/Maracanã. O tema Infâncias, Cultura e Relações Intergeracionais na vida cotidiana, constituiu a conferência "Questão étnico-racial e questão geracional na infância", tendo como centralidade questões fortemente candentes nos Estudos da Infância: questões étnico-raciais e questões geracionais, problematizando como essas interseccionalidades (Collins, 2019) repercutem na vida cotidiana de crianças brasileiras, especialmente de crianças das classes populares que vivem em periferias das grandes metrópoles, tais como as favelas e periferias urbanas do estado do Rio de Janeiro. Nesse texto-pretexto, escolhi falar dessa outra que estamos nomeando como a criança das classes populares, a que vive em periferias urbanas, em favelas e bairros populares. Aquelas que apesar de "infans"- sem fala, ousam falar, se falam e são falados por nós, professoras e pesquisadoras da infância. Tomando a nossa proposta de conversa como um dispositivo para um encontro (Deleuze, 1998), busquei falar dessa Outra, recorrendo às minhas anotações do dia da conferência, e as vozes de autores (as) com os quais dialogo em meus estudos, pesquisas e trabalhos cotidianos em diferentes territórios da cidade (Tavares, 2019), entendendo a cidade contemporânea como um lugar de encontros: bons e ou maus encontros. Sobretudo um lugar de encontros intergeracionais, de possibilidade de produção do (con)viver.

palavras-chave: direito à cidade; infâncias; natalidade; relações inter geracionais; hospitalidade.

\section{infancias, ciudad y relaciones intergeneracionales en la vida cotidiana}

resumen

El presente artículo deriva de mi participación en el II Congreso de Estudios de la Infancia: Politizaciones y Estesias, realizado en septiembre de 2019, en la Universidad del Estado de Rio de Janeiro/Maracanã. Mi presentación, intitulada Infancias, Cultura y Relaciones Intergeneracionales en la vida cotidiana, constituyó la conferencia "La cuestión étnico-racial y la cuestión generacional en la infancia", teniendo como centro cuestiones fuertemente candentes en los Estudios de la Infancia: las cuestiones étnico-raciales y las cuestiones generacionales, problematizando como estas interseccionalidades (Collins, 2017) repercuten en la vida cotidiana de los niños(as) brasileños(as), especialmente los/las de clases populares que viven en las periferias de las grandes metrópolis, tales como las "favelas" y periferias urbanas del estado de Rio de Janeiro. En este texto-pretexto, elegí hablar de este otro que estamos nombrando como el niño/la niña de clases populares, que vive en periferias urbanas, en "favelas" y barrios populares. Aquellos(as) que a pesar de infans-sin habla, se atreven a hablar, hablan y son hablados por nosotros, profesoras e investigadoras de la infancia. Tomando nuestra propuesta de conversación como un dispositivo para un encuentro (Deleuze, 1998), busqué hablar de este(a) Otro(a), recurriendo a mis anotaciones del día de la conferencia y a las voces de autores(as) con los cuales dialogo em mis estudios,

\footnotetext{
${ }^{1}$ E-mail: mtgtavares@yahoo.com.br
} 
investigaciones y trabajos cotidianos en diferentes territorios de la ciudad (TAVARES, 2019), entendiendo la ciudad contemporánea como un lugar de encuentros: buenos y/o malos. Sobre todo, un lugar de encuentros intergeneracionales, de posibilidad de producción del (con)vivir.

palabras clave: derecho a la ciudad; infancias; natalidad; educabilidad; hospitalidad.

\section{childhoods, city and intergenerational relationships in everyday life}

abstract

This article derives from my participation in the II Congress of Childhood Studies: Politicizations and Aesthetics, held in September 2019, at UERJ/Maracanã. My speech entitled Childhoods, Culture and Intergenerational Relations in everyday life, was delivered in the conference "The ethnic-racial issue and the generational issue in childhood" having at its core extreme burning issues in Childhood Studies: both ethnicracial and generational issues, arguing how these intersecting points (Collins, 2017) have effects on the daily life of Brazilian children, especially children from the popular classes who live in the outskirts of the big cities, such as the slums and urban borders of the state of Rio de Janeiro. In this pre-text, I chose to speak of this Other, named the child from the popular classes, the one who lives in the outskirts, in slums and popular areas. Those who, despite being infants deprived of speech, dare to speak among themselves and are spoken of by us, teachers and researchers of childhood. Considering our proposal of establishing conversation as a device for an encounter (Deleuze, 1998), I tried to speak of this Other, using my notes from the day of the conference, and the voices of authors with whom I dialogue in my studies, researches and daily work in different territories of the city (Tavares, 2019), understanding the contemporary city as a place of encounters, both good and bad. Above all, the city is a place of intergenerational meetings where the co-existence is possible.

key words: right to the city; childhoods; birth rate; educability; hospitality. 
estar com os outros e outras- conversar

- Como diz o outro. Que outro? E desde quando ele se chama Outro? Estranho nome, este, que não identifica, não responsabiliza, não consta de nenhum registro civil: Outro nascido em tal data, em tal lugar, do sexo masculino. Por que nunca se diz: Como diz a outra? A Outra não diz nada, limita-se a ouvir o Outro, se é que ouve?

(Carlos Drummond de Andrade, 1979).

Arrisco-me à escrita desse texto-pensado e tecido como um pretexto para um encontro com um(a) possível leitor(a). Um Outro.Uma Outra. Que talvez possam desejar esse encontro porque não temem os encontros- bons e maus encontros, porque sabem que tudo é apenas um encontro no universo: “encontram-se pessoas (e às vezes sem as conhecer nem jamais tê-las visto), mas também movimentos, ideias, conhecimentos, entidades" (Deleuze, 1998, p. 14). O texto assim é tomado como um pretexto para entabular uma conversa. Conversar é uma palavra derivada do latim cum -, com e versar-dar voltas. Assim, gostaria de pegar o(a) leitor(a) pela mão e dar algumas voltas, enquanto apresento o lugar, invariavelmente polifônico, no qual um texto é, de modo geral, tecido.

Procurando a mão de Outros, inicio a conversa narrando que o presente texto deriva de minha participação no II Congresso de Estudos da infância: Politizações e Estesias, realizado em setembro de 2019, na UERJ/Maracanã. A minha fala intitulada Infâncias, Cultura e Relações Intergeracionais na vida cotidiana, constituiu a conferência "Questão étnico-racial e questão geracional na infância”, compartilhada com o professor Renato Nogueira (UFRRJ), tendo como centralidade questões fortemente candentes nos Estudos da Infância: questões étnico-raciais e questões geracionais, problematizando como essas interseccionalidades (Collins, 2019) repercutem na vida cotidiana de crianças brasileiras, especialmente, de crianças das classes populares que vivem nas periferias das grandes metrópoles, tais como as favelas e periferias urbanas do estado do Rio de Janeiro.

Nesta perspectiva, a citação utilizada como epígrafe introdutória deste textoconversa me parece ser emblemática do complexo lugar ocupado pela infância na contemporaneidade. Acompanhamos surpresos a velocidade das transformações 
cotidianas, a tensão entre os inúmeros discursos estruturados sobre as diferentes infâncias e as condições materiais, objetivas e subjetivas, nas quais essas múltiplas infâncias concretamente se realizam, principalmente nos espaços institucionalizados que se ocupam da educação de crianças pequenas.

O escritor Carlos Drummond de Andrade, em seu poema O Outro (1979), registra de maneira irônica o fato de sempre se falar em nome do outro, sem jamais especificar quem é esse outro, observando de forma bastante irreverente que nunca se fala em nome da outra. Nesse texto-pretexto, escolhi falar dessa outra que estamos nomeando como criança das classes populares, a que vive em periferias urbanas, em favelas e bairros populares. Aquelas que apesar de infans-sem fala, ousam falar, se falam e são falados por nós, professoras e pesquisadoras da infância. Tomando a nossa proposta de conversa como um dispositivo para um encontro (Deleuze, 1998), buscarei falar dessa Outra, recorrendo às minhas anotações do dia da conferência, e as vozes de autores (as) com os quais dialogo em meus estudos, pesquisas e trabalhos em diferentes territórios da cidade (Tavares, 2019), entendendo a cidade contemporânea como um lugar de encontros: bons e ou maus encontros. Sobretudo um lugar de encontros intergeracionais, de possibilidade de produção do (con)viver.

Em São Gonçalo², município bastante populoso do Estado do Rio de Janeiro, e território de nossas pesquisas interessadas, a pluralização das experiências infantis, os diferentes modos de ser criança, bem como a heterogeneidade da infância como categoria geracional, vem colocando questões nodais para as diferentes agências sociais reguladoras da infância, como o Estado, a família, a escola, os massmedia. No caso da escola da pequena infância, sobretudo no interior de suas práticas cotidianas, amplia-se a perplexidade daqueles e daquelas que apresentam dificuldades para compreender o movediço estatuto contemporâneo da infância: os/as professores/as e demais profissionais que atuam na Educação Infantil.

\footnotetext{
2 O município de São Gonçalo, segundo dados do IBGE (2012), conta com mais de um milhão de habitantes, apresentando um altíssimo, acelerado e não planejado crescimento populacional. Contando com mais de noventa e dois bairros, a cidade é um retrato vivo das "desigualdades multiplicadas", expressas em seus bolsões de pobreza e violência urbana, que constrangem principalmente as crianças pequenas.
} 
Etimologicamente a palavra infância deriva-se do latim infant que significa aquele que não fala, aquele que vem sendo falado pelos diferentes discursos e saberes, sejam estes discursos médicos, jurídicos, psicólogos, pedagógicos, midiáticos, pelos estudos sociais da infância, etc. Porém, no terreno concreto, miúdo da vida cotidiana, multiplicam-se a polifonia das vozes infantis: a criança reivindica a sua saída dos bastidores do cenário sociocultural, demandando também o seu reconhecimento como ator social (Faria; Finco, 2011).

Deste modo, intencionando cum-versar sobre um conjunto de questões epistêmicas, políticas e éticas derivadas da temática "Infância, Cultura e Relações intergeracionais na vida cotidiana", organizei o texto em dois eixos: o primeiro ancora-se no desafio epistêmico de pensar a experiência do encontro intergeracional, do acolhimento do recém-chegado (Arendt, 1961), sobre convivência e hospitalidade na cidade contemporânea, pensada como um espaço do estar junto(Tavares, 2019). O segundo eixo reflexivo dedica-se a problematizar percursos investigativos que atravessam a experiência da cidade, direito à cidade de crianças que vivem e produzem suas educabilidades (Freire, 1979,1990) em periferias urbanas na cidade de São Gonçalo, o segundo maior município em densidade populacional do Estado do Rio de Janeiro e território físico, geográfico e simbólico de (re)invenção cotidiana da infância.

\section{A experiência do encontro: natalidade e hospitalidade na cidade contemporânea}

Estar junto por amor ao mundo. A permanência do que chamamos de mundo nos parece repousar, então na natalidade (Arendt, 1961), na renovação incessante das gerações, no nascimento de homens e mulheres novos, que tenham "cuidado com o mundo"3, com os diferentes Outros e Outras que o constituem. Para a pensadora política Hannah Arendt, como a própria gostava de ser chamada, a nossa capacidade para ação está inscrita em nossa natalidade: é porque nascemos que somos capazes de agir. Para a pensadora, agir significa então, realizar o que não pode ser previsto, permitir que aconteça o improvável, fazer o impossível. Em

\footnotetext{
${ }^{3}$ Cuidado com o mundo, expressão de Hannah Arendt, que significa criar, pela ação e pela palavra, um lugar de convivência entre homens e mulheres resgatando-o do deserto que ele pode vir a se tornar (1995).
} 
outras acepções, o que se diz a partir desse conceito político arendtiano, a natalidade, é não somente a nossa capacidade para realizar o novo como imprevisível e incalculável, mas que fundamentalmente é apenas nessa condição que podemos nos realizar plenamente (Arendt, 1995).

Ainda segundo Arendt (1995), o mundo que resulta de nosso agir existe justamente em função do fluxo constante dos recém-chegados porque não paramos de chegar, porque somos constantemente substituídos por novas gerações, dizemos que o mundo ainda não foi finalizado. Assim, o mundo é um estado permanente de (re)construção e aperfeiçoamento porque continuam chegando novas e novas crianças. E se a natalidade é por assim dizer, a origem do mundo, o que vemos na origem do mundo é um estado de hospitalidade (Farias, 2018).

A (inter)relação entre natalidade e hospitalidade embora pareça evidente, não é tão óbvia assim. É importante afirmar então, que nascer já seria instalar um estado de hospitalidade: "o nascimento talvez seja o estado de hospitalidade por excelência" (Farias, 2018, p. 84), pois do ponto de vista da natalidade, o mundo seria um recomeçar permanente, sendo que para Arendt (1995), o mundo que resulta de nossa obra, existe justamente em função do constante influxo dos recém-chegados. E se a natalidade é, por assim dizer, o fundamento da origem do mundo, o que vemos na origem do mundo é um estado de hospitalidade (Farias, 2018, p. 85) É esse estado de hospitalidade instado na origem do mundo que nos provoca a pensar as conexões entre a natalidade como categoria da ação-política (Arendt, 1995) e a questão ético-política da hospitalidade (Derrida, 2003). Nesse sentido, o mundo que resulta de nossa condição obreira, só existe em função do constante influxos dos recém-chegados, uma referência ao nascimento de crianças no contexto da teoria política de natalidade de Arendt (1995), mas se relacionarmos essa questão, vinculando-a ao conceito de hospitalidade, não poderíamos ampliar o conceito, considerando que todos nós somos de alguma maneira recém-chegados? A condição de estarmos constantemente em movimento, em fluxos, adentrando em territórios, lugares, contextos e (des)encontros, não deveria expressar uma constante atualização da natalidade na própria dinâmica que configura diferentes expectativa em relação a nós mesmos e ao Outro? 
Por exemplo, quando um refugiado ou um estrangeiro se instala em um outro país, em um outro território cultural, ele ou ela será desafiado a aprender a cultura do novo país, e, portanto, a nascer de novo partindo desse sentido ampliado de natalidade, assimilando outros repertórios culturais, muitas vezes, totalmente estranhos a sua cultura de origem. E aqui, como no nascimento de uma criança, encontramos as condições de realização do improvável, do imprevisto, do impossível. A dinâmica da presença-ausência, disposta na hospitalidade e na natalidade, configura o que estamos chamando de ação política (Arendt, 1995; Derrida, 2003).

De fato, o que fazemos quando agimos é começar de novo, e isso implica a capacidade de desencadear processos, produzir acontecimentos, movimentar e mobilizar potências outras na vida cotidiana. Isso significa produzir outras possibilidades para nós e os Outros, diante da provisoriedade do mundo que nos cerca, e que somos desafiados e instados a cuidar (Tavares, 2003). Porém, em diálogo com Castro (2013) e Freitas (2018), a questão intergeracional enquanto tema/ problema de nossa conversa é uma problemática contemporânea nodal, que afeta fortemente todos os campos da vida humana, sobretudo a questão da natalidade (Arendt, 1995; 2006) e a questão da hospitalidade (Derrida; Dufoumantelle, 2003; Freitas, 2028) em seus sentidos filosóficos e políticos mais amplos.

Castro (2013) afirma que tudo indica que a reciprocidade do pacto geracional foi sendo progressivamente desarticulada nas sociedades capitalistas modernas, engendrando a importância de se inventar outras formas de solidariedade entre as gerações. Se, anteriormente, a vinculação solidária entre adultos, jovens e crianças, principalmente entre pais e filhos, nas famílias, mesmo no interior de diferentes classes sociais, constituía um dos principais dispositivos de trocas e intercâmbios geracionais, atualmente na contemporaneidade, essas trocas parecem ser bem menos perceptíveis. Assim, para Castro (2013), a distância que separa adultos, jovens e crianças parece ser cada vez mais encurtada, ou até mesmo inexistente:

À medida que se antes a troca geracional calibrava o esforço de ambas as gerações na direção de aproximar reciprocamente as distâncias, agora essas parecem bem menos perceptíveis. O percurso, ou seja, correr por intermédio de, vem sendo substituído pelo curso, correr para chegar a, e tanto os mais velhos como os mais 
novos se impõem a caminhada em direção às benesses do desenvolvimento material e tecnológico (Castro, 2013, p.57).

Para dar maior visibilidade a essas questões sobre a posicionalidade da infância e a especificidade das trocas geracionais no contemporâneo, Castro (2013) recorre ao filme "Ninguém pode saber" (2004), do cineasta japonês Hirokazu Koreeda, no qual o diretor narra a história de uma mulher com seus quatros filhos (todos de pais diferentes), que aluga um apartamento na cidade de Tóquio, no Japão. Segundo as regras desse apartamento é proibido morar mais de três pessoas, o que leva as crianças estarem sempre se escondendo dos demais moradores do prédio onde moram.

Sem desejar me alongar na narrativa fílmica de Koreeda, trago algumas questões problematizadas por Castro (2013), buscando colocá-las em diálogo no presente texto, relacionando-as às questões da natalidade e hospitalidade, pensadas como questões nodais na troca geracional. A primeira delas é o papel de Akira, o filho mais velho de 12 anos, que se multiplica nas tarefas de cuidar dos dois irmãos menores. No filme, as crianças ficam em casa a maior parte do tempo até porque não podem ser vistos pelos vizinhos por morarem de uma forma ilícita, se expondo a serem denunciados aos proprietários do apartamento. Todos eles, mesmo o Akira, nunca foram à escola, o que parece ser revelador da "dispensa do percurso, assim como a ausência do movimento dos mais novos em relação a um outro tempo para além do presente" (Castro, 2013, p. 59).

O filme coloca em questão um cenário no qual as gerações mais velhas parecem não mais desejar estar disponíveis para mediar os itinerários biográficos dos mais novos, isto é, os percursos das duas gerações não estão mais definidos em termos de "antes' e depois", nem de ultrapassagens de um lugar geracional a outro (CASTRO,2013). E continuando o diálogo com Castro e Koreeda, no filme "Ninguém pode saber", é importante assinalar a falta de hospitalidade dos demais adultos moradores do prédio frente à questão da mulher e seus filhos, remetendonos à interseccionalidade de questões de gênero e classe também presentes na ausência de acolhimento de Akira e seus irmãos. Castro ainda reitera a problemática intergeracional, referindo-se à questão das distâncias geracionais terem se 
encurtado, fazendo com que adultos e crianças tenham se tornado parecidos: "as crianças adultizadas e os adultos infantilizados" (Castro, 2013, p. 60).

Por outro lado, em 2011, quase uma década depois, Hirokazu Koreeda retorna às telas com o filme "O que mais desejo", que também tematiza a questão da infância e as relações das crianças com os adultos. Ao contrário de "Ninguém pode saber", o filme "O que mais desejo" anuncia um "reencontro possível entre gerações e, portanto, o movimento de busca de uma reciprocidade geracional em meio às enormes transformações do mundo contemporâneo (Castro, 2013, p. 67).

O filme narra sob o olhar de Koichi, o filho mais velho, as relações de uma família cujos pais e filhos foram separados pelo divórcio, vivendo cada um deles em cidades diferentes na ilha Kyshu no Japão. Koichi protagoniza o movimento de buscar a realização do que mais parece desejar: a reunião de sua família.

Esse desejo parece ser distante e quase impossível, à medida que o seu próprio irmão que mora com o pai, a mãe e o próprio pai parecem se importar muito com a separação da família. Ao ouvir de um colega de escola que os desejos podem ser realizados se forem evocados no ponto de intersecção de dois trens, e sabedor de a linha de trem bala vai chegar na ilha onde vive, Koichi decide se aventurar a ir até o ponto de cruzamento dos trens para nesse lugar evocar o seu desejo de reunir a sua família (Castro, 2013).

O filme narra como as crianças, Koichi, seu irmão Ryu, bem como amigos e amigas de ambos vão construindo modos de chegar ao lugar de evocação dos desejos. E com cada um vai produzindo o que deseja desejar (idem). Na trama fílmica, o que fica evidente não é uma "infância infantilizada”, mas também não é uma "infância adultizada", como no filme "Ninguém pode saber".

Koichi ao planejar estrategicamente a viagem em seus pormenores: gastos, rota, formas de burlar o controle dos adultos da família (avô, pai e mãe) sobre ele e seu irmão, vai refletindo sobre a separação de sua família, sobre a vida de cada um deles de forma separada, Koichi vivendo com a mãe e o avô, e o seu irmão Ryu vivendo com o pai em outra cidade. Ao falar por telefone com o pai, Koichi se surpreende quando este "lhe diz que quer que ele cresça para se importar com mais 
coisas que a própria vida, Koichi pergunta ao pai que coisas seriam essas, ao quê o pai responde: com o mundo (Castro, 2013, p. 69).

O retrato da infância trazido por Koreeda neste filme nada tem a ver com a narrativa das crianças de Ninguém pode saber, "em que despojadas de qualquer enlace com os adultos, como passado ou a memória, são crianças cujo desejo não as leva mais longe do que o dia a dia comezinho e sem perspectivas" (Castro, 2013, p. 70).

Em "o que eu mais desejo", Koreeda parece reconstruir o potencial de transformação não apenas da infância, mas das relações intergeracionais. Se no filme "Ninguém pode saber" as relações intergeracionais pareciam estar moldadas na indiferença mútua, em "O que mais desejo" se anuncia a busca de um encontro possível, "no qual a palavra pode fecundar" (Castro, 2013, p. 70).

O filme de Koreeda pode ser visto como uma alegoria de outra infância, no qual as crianças podem estar no mundo como sujeitos, podendo descobrir por si e compartilhar com os Outros "a palavra que expressa seus desejos, angústias e emoções" (Castro, 2013, p. 71). Os dois filmes de Koreeda nos parecem ser emblemáticos para pensarmos diferentes maneiras de se viver a(s) infância(s), as trocas geracionais sem tantos maniqueísmos e reducionismos que retiram a imponderável complexidade que as atravessam.

Os filmes de koreeda como dispositivos de pensamento, afirmam a pluralidade da infância, bem como a possibilidade de encontros geracionais marcados pelo acolhimento, tanto do recém-chegado, como dos adultos que se colocam disponíveis para a experiência do encontro. Os filmes nos mostram que as crianças transitam em outros circuitos de relações com os outros, além do adulto, tal como entre crianças e crianças, que inspiram seus processos de subjetivação (Castro, 2013)

Diante dessas questões, tomar a natalidade e a hospitalidade como dispositivos conceituais que possibilitam as trocas geracionais, nos convidam a pensar o encontro geracional como uma responsabilidade de estar no mundo, pois:

O arquétipo de toda responsabilidade é a do homem para com outro homem, considerando que essa faculdade da responsabilidade faz parte do ser do homem de modo tão inseparável quanto a sua capacidade de fala. (Courtine-Denamy, 2004, p. 196). 
E do ponto de vista dos meus estudos, o lugar por excelência dos encontros e trocas geracionais é a cidade contemporânea. A cidade pensada na perspectiva de Santos (1996), isto é, como o lugar no qual o mundo se move mais e os homens também, espaço da copresença e dos encontros. Bons e ou maus encontros, como os nossos per-cursos de trabalho vem afirmando em São Gonçalo.

\section{apre(e)ndendo a cidade: o direito à cidade como pressuposto da convivência intergeracional}

É difícil compreender como no vasto mundo falta espaços para os pequenos. Carlos Drummond de Andrade, 1985.

Em diferentes contextos da história humana, as cidades têm sido estudadas e representadas por inúmeros pensadores nas diversas áreas do conhecimento. Lugar do simbólico, onde se produz a história, cenário das tramas humanas, a cidade pode ser lida, segundo Machado (2002, p.213), como: “Macrocosmo social, encontro de funções e sinergia de criações, texto e discurso, a cidade atravessa as ciências humanas e fecunda artes e letras como questão (o que é a cidade?) e como problema (Por quê a cidade?) ".

Em nosso longo processo de pesquisa na rede escolar de São Gonçalo, desde 1998, com o início do percurso de doutorado, e finalizado com o trabalho da tese "Os pequenos e a cidade: o papel da escola na construção de uma alfabetização cidadã"(Tavares, 2003), tomar a cidade como um livro de espaços, cujas práticas e relações sociais nos parecia epistemicamente importante investigar e ler com os sujeitos escolares, implicou na complexificação do conceito de alfabetização para além de sua acepção usual na cultura escolar. Isto é, implicou tomarmos a "cidade como um problema" como nos desafia Machado (2002).

Do ponto de vista dos estudos realizados, venho afirmando que ler o mundo é também ler o espaço. Isto implica em pensá-lo como fruto da construção social e histórica da ação humana. Assim, ler o mundo é estudar a sociedade; é estudar o processo de humanização a partir do território usado, conforme nos ensina Santos (1996). É na contemporaneidade, especialmente, estudar as relações sociais com e na cidade, pois por ser a cidade um meio técnico-científico-informacional (Santos, 1996) 
por excelência, seria um lócus da densidade comunicacional, uma arena cultural, espaço de conflitos disputas e negociações (Tavares, 2003).

Um outro conceito importante e que vem sendo trabalhado no desenvolvimento de nossa pesquisa, é o de educabilidade utilizado por Paulo Freire (1979; 1990). Na concepção de Paulo de Freire, o conceito de educabilidade vai além do direito à educação formal, englobando principalmente, a construção de saberes e práticas que possibilitam mudanças na realidade tanto do (a) educador (a), como na relação com as próprias crianças. A educabilidade corresponderia a um saber construído a partir do conhecimento da realidade histórico-social, da realidade espacial concreta, bem como do conhecimento intercambiado entre todos os sujeitos que estão de alguma forma se relacionando no contexto social mais amplo.

Nessa perspectiva, podemos entender que o saber/conhecimento não é produzido apenas na relação escolar: professor/a, crianças e objetos do conhecimento, mas é construído em contextos muito mais amplos, nos quais podemos incluir os familiares destas crianças, isto é, os diferentes adultos com os quais se relaciona, os seus pares preferenciais nos diferentes espaços de brincadeiras, e por que não, nas relações construídas nos diferentes espaços vivenciados pelas crianças na cidade.

Em nossa pesquisa, vimos aprendendo que o espaço físico e territorial vivenciado pelas crianças pequenas, em muito influencia a construção de seu modo de ser, de seus saberes e concepções de mundo. Neste sentido, podemos dizer que para Freire (1990), a educabilidade é um processo político e epistêmico, no qual os espaços praticados pelas crianças, mesmo não sendo espaços institucionalizados como as escolas de Educação Infantil e/ou creches, possibilitam a construção de culturas infantis (Corsaro, 2009). O conceito de educabilidade parece favorecer um campo simbólico e material no qual as crianças pequenas podem construir identidades e relações de pertencimento com o território vivido.

Em nossa pesquisa tem sido fundamental entender como este processo "de pensar e pensar-se na cidade" (Tavares, 2003) ocorre também nas escolas da pequena infância, já que as pré-escolas e creches em São Gonçalo não são ilhas isoladas das influências que o território da cidade propicia. A escola de Educação 
Infantil é um dos importantes componentes territoriais da cidade gonçalense, sendo possível compreender que a sua visibilidade e presença na cidade, de modo geral, provoca um impacto cultural/relacional e uma significativa mudança comportamental na imagem das infâncias no espaço público.

Com a presença da criança pequena na cidade, em suas práticas espaciais e deslocamentos a "caminho da escola", também é visível o despreparo da própria cidade frente às demandas infantis por transporte, por segurança, por calçadas e espaços arborizados, pelo direito de ir e vir, pelo seu direito à cidade de forma mais ampla.

A partir dessas questões, tornou-se fundamental em nossos percursos investigativos, a desnaturalização sobre o significado e o impacto das crianças pequenas usarem os territórios da cidade, bem como investigar o que pensam, conhecem, representam, desconhecem sobre o caminho da escola: o que as crianças pensam sobre o espaço de suas pré-escolas e creches? Como experimentam o caminho de seus bairros até a entrada de sua pré-escola? Quais são os seus contextos e espaços de descobertas? O que elas pensam sobre a sua rua? O seu bairro? Seus espaços de brincadeiras? De que tem medo e insegurança? Quais são os territórios das infâncias na cidade? Por isso, buscamos em Freire $(1979,1990)$ entender que a questão da educabilidade pode ser lida como a capacidade da criança de participar de processos de discussão do direito à cidade (Lefebvre, 1991), de expandir as suas experiências nos diferentes espaços da cidade, sendo esta compreendida também, como um agente produtor de espaço que gesta e aporta sentidos às suas espacialidades, produzindo espaços e territórios infantis na cidade.

Para aprofundar essas e outras questões políticas epistêmicas da pesquisa sobre infância e cidade, busco o diálogo atento com escritos da filósofa alemã Hannah Arendt, principalmente com a sua convicção de pensar a criança como um recém-chegado. A referida autora escreveu em 1961, um ensaio sobre "A crise na educação" - no qual, em nossa leitura crítica, fez uma análise muito contundente de como a crise no mundo acabara por afetar a educação, bem como a relação entre a infância e a escola da infância. 
Ainda no mesmo artigo citado, para Arendt a educação precisa ser assumida como uma responsabilidade social com os pequenos e sua inserção no mundo social mais amplo. A autora exemplifica a questão da falta de cuidado com o recém-chegado, por exemplo, no evento de Little Rock, nos anos 1950, nos EUA, quando uma adolescente negra teve que ser escoltada para entrar na escola no início do processo de abertura das escolas públicas para crianças negras. Arendt fez uma dura crítica aos adultos que, sendo responsáveis pelas crianças, deixaram que os problemas destinados à "esfera pública" as afetassem diretamente, como nesse acontecimento.

Como pensadora da política, Arendt não pretendeu estudar nenhuma solução e prescrições para o campo educacional, e retornando ao recém-chegado, conceito em análise, que significa aquele que nasce para o "mundo" - outro conceito da autora, o qual não se trata do mundo físico, mas sim, da entrada das crianças na sociedade a qual pertencem. E ainda segundo a autora, caberia aos pais, professores e adultos proteger a criança do mundo, e o mundo da criança, isto é, não permitindo que concepções adultocêntricas contaminem a infância, ao mesmo tempo, não impedindo que a renovação que cada criança traz consigo, esfacele a tradição (Arendt, 1961).

Arendt (1961) compreende que cada nascimento traz consigo novas possibilidades as quais, se desenvolvidas com pré-conceitos, se findam antes que floresçam. A criança pequena tem direitos declarados de importância inegável, que são sistematicamente violados nas sociedades capitalistas ocidentais, dentre eles o direito à cidade. Direito este que se não for atrelado à uma cultura pública, isto é, sem o atrelamento às políticas públicas de uso e participação infantil na cidade, além de um forte compromisso das instituições educativas, se tornam muito suscetível, impossíveis de serem efetivamente (e culturalmente) praticados.

Neste diálogo com Arendt, defendo que a participação da criança pequena na construção do conhecimento nas escolas de Educação Infantil de forma a abranger o seu contexto citadino, não só legaria o sentimento de pertença ao lugar que se vive, como também poderia educá-la como cidadã responsável pelo "mundo". Isso implica a compreensão da Educação Infantil como um espaço-tempo singular da Educação Básica, caracterizando-se como um portal de boas-vindas às 
crianças pequenas para adentrar na "esfera pública", conforme nos provoca a pensar Arendt. Assim,

[...]a escola é antes a instituição que se interpõe entre o domínio privado do lar e o mundo, de forma a tomar possível a transição da família para o mundo. Não é a família, mas o Estado, quer dizer, o mundo público, que impõe a escolaridade. Desse modo, relativamente à criança, a escola representa de certa forma o mundo, ainda que o não seja verdadeiramente (Arendt, 1961, p.10).

Conhecer e explorar os diversos territórios e signos da cidade e praticar formas e modos distintos de usufruir a cidade, de reconhecer-se nela, de realizar o (re) conhecimento dos espaços de produção da vida urbana, significa para as crianças pequenas impregnar-se da cultura em seu sentido mais amplo, compreendida como um bem comum, fruto do trabalho humano e da ação do tempo (Tavares, 2003).

Do ponto de vista geracional, os adultos possuem o domínio do mundo por habitá-lo antes dos pequenos, dos recém-chegados que, ainda, não o possuem por desconhecê-lo. Cabe a eles, diferentes adultos, apresentá-los a esse mundo, e além disso, mostrar esse espaço-mundo como possibilidade de construção de si e do outro como comum, como diferente, mas com o estatuto político de igual. Esse talvez seja o sentido mais abrangente do papel da educação e responsabilidade de todos os adultos: dar boas-vindas ao recém-chegados ao mundo no qual já vivemos. Acolhê-los com hospitalidade.

Essa questão implica em discutir como nós (re) apresentamos nossos mundos aos recém-chegados, especialmente para que os pequenos tenham como herança o que a autora chama de amor mundi (Arendt, 1961). Não se trata de pensar a educação das infâncias a partir de uma concepção ingênua e romântica da criança, mas de pensar a criança como capaz e comprometida em assumir a responsabilidade por esse espaço, mesmo com todos os problemas que o mundo possa ter. Implica em tomá-lo como seu e lutar por ele, lutar pela vida. E como na maioria das vezes para a criança pequena gonçalense, o mundo é a cidade, implica em aprender a lutar por ela, para nela viver com dignidade (Santos, 1996).

Em suas obras Arendt, demonstra forte valoração pela história. Assim, a tradição, que é um legado importantíssimo para a autora, constitui um exercício de pensamento, formas de pensar a cidade em diálogo com as suas histórias e 
memórias; isto é, aprender a ler a cidade implica na capacidade de vivê-la conhecendo suas histórias, sendo constituído por elas.

A escola da pequena infância poderia ser um espaço maior de experimentações que propiciaria muitos sentidos às descobertas dos recém-chegados, ainda carece de impulsionar as crianças à compreensão do sentido das tensões vividas nos espaços públicos, proporcionando-lhes possibilidades de novas discussões que incluam a questão da participação do coletivo infantil, entendendo a importância de se expandir a autonomia destinada às crianças na vida cotidiana.

Do ponto de vista da participação política do recém-chegado, entendo ser crucial que o seu direito à participação possa ser mediado e respeitado pelos adultos, aqui representados por professores/as e outras pessoas adultas que trabalham na escola da pequena infância, pois (re) apresentar o mundo, papel dos adultos, implica em fazer seleção, escolhas, julgamento, silenciamentos (Tavares, 2016).

E na perspectiva do direito dos recém-chegados à cidade, entender como o "mundo", a cidade, o bairro, a rua, a escola se constituiu em seu tempo histórico, faz com que o "novo" assuma o "velho" que nele existe e se sinta preparado e livre para pensar/conhecer outras possibilidades. Dessa forma,

A nossa esperança reside sempre na novidade que cada nova geração traz consigo. Mas, precisamente porque só nisso podemos basear a nossa esperança, destruímos tudo se tentarmos controlar o novo que nós, os velhos, pretendemos desse modo decidir como deverá ser (Arendt, 1961, p.12).

E ainda, na prática, a primeira consequência que daqui decorre é a compreensão de que a função da escola é ensinar às crianças o que o mundo é, dialogando com elas sobre a arte de viver neste mundo. Uma vez que o mundo é velho, sempre mais velho do que nós, aprender implica, inevitavelmente, voltar-se para o passado, sem ter em conta quanto da nossa vida será consagrada ao presente (Arendt, 1961, p. 13).

Nesse sentido, aprender o direito à cidade, e tornar-se parte de um coletivo que o reivindica, exige processos de compreensão de si e do outro, bem como a importância de se construir uma familiaridade com o espaço compartilhado, entendendo o contexto da produção histórica da cidade, a formação social do lugar, 
as lutas pelo espaço urbano, à medida que aprender a ler a cidade como um livro de espaços (Tavares, 2003) implica em todo um trabalho acerca do olhar sobre o mundo. “O mundo mais uma vez não é uma realidade original que atua por trás da visão, da perspectiva, mas, sim, uma evidência, o "lá está" ou "estar lá", que requer sorte ou arte para fazer acontecer" (Masschelein, 2014, p. 172). E um trabalho para educar o olhar seria tomar a cidade com os recém-chegados como um lugar de leituras e experimentações éticas, políticas e estéticas, tomando a cidade como um livro de espaços (Tavares, 2003).

Na contramão de uma perspectiva instrumental da aprendizagem da leitura e da escrita, entendemos, que, se na escola de Educação Infantil, professores (as) e crianças pudessem problematizar a cidade, lê-la em sua "geografia existencial" 4 , descrevendo-a, narrando-a, escrevendo-a de acordo com os diferentes sentidos e linguagens, uma outra experiência alfabetizadora poderia estar sendo construída.

Experiência alfabetizadora que implicasse em narrar à cidade, tornar o contexto citadino um texto narrativo. Ler a cidade implicaria em dela se aproximar, fazendo uso, não apenas de forma instrumental, mas através de práticas alfabetizadoras, que ao aprender a ler o espaço da cidade, pudessem conjugar desejo, criação, necessidade e responsabilidade - movimento fundamental, individual-coletivo para se enunciar/construir escolas/cidades mais agenciadas com a vida coletiva, como por exemplo, as experiências das aulas-passeio pensadas por Freinet (1973), e ou as caminhadas realizadas por Jan Masschelein em sua educação formadora de mundo(2014), ou nas marchas do Movimento Zapatista, que faz do seu caminhar perguntando o seu manifesto ético e político-cultural (Labbucci, 2013).

Assumimos assim, o compromisso ético e político e, portanto, epistêmico, de lutar para que a escola da infância, em sua multiplicidade e potência possa ser um espaço gerador de práticas democráticas, um lugar culturalmente rico, tanto de histórias e memórias distintas, como também de afeto, cooperação e solidariedade.

\footnotetext{
${ }^{4}$ Para Milton Santos, as relações do homem com o seu espaço são relações temporais, transcendentes e criativas. Assim, a geografia existencial de uma cidade implicaria a recriação desse espaço, como o seu espaço de viver. Para Santos (2000), a cultura é produzida nos lugares, as ideias são produtos da vivência do lugar.
} 
A escola da infância animada por esses valores, pelo reconhecimento dos recémchegados como legítimos outros (Maturana, 1998) poderia se tornar assim, um campo fértil para que a aventura do conhecimento possa aí se instalar, alimentando sonhos e práticas pedagógicas que possam produzir pensamentos científicos, filosóficos, políticos, artísticos, éticos e humanitários, possibilitando que as diferentes culturas possam ser um dos principais amálgamas de nossas construções identitárias.

\section{infância, cidade e encontros intergeracionais: considerações finais, porém provisórias}

Fundamentada em um longo percurso de trabalho (Tavares, 2003; 2009; 2010; 2016; 2018) no qual o longo e minucioso trabalho de campo, a produção do que chamamos empiria, longe de ser apenas um espaço de coletas de dados e construção de conhecimentos, tem possibilitado um movimento de ação-reflexão-ação coletiva sobre o conhecimento, buscando corroborar o papel de pesquisa como produção intencional de conhecimento numa perspectiva emancipatória, pois, segundo Boaventura de Sousa Santos (2000), todo processo de produção do conhecimento implica e nos desafia aos processos de autoconhecimento, isto é, ao conhecimento de si e do mundo que nos atravessa.

Como anunciamos nas palavras iniciais deste artigo, o desafio de buscar pesquisar com crianças, enxergando-as como Outras, sujeitos de direitos e coparticipantes de nossos processos de pesquisa, com protagonismo e participação ativa nos exige pensar e problematizar o caráter ético da pesquisa, a concepção de ciência e a concepção de conhecimento que fundamenta o nosso trabalho investigativo.

Desse modo, pensar a pesquisa como uma experiência de conhecimento traz à tona questões vinculadas à subjetividade do (a) pesquisador (a) e, consequentemente, ao caráter do conhecimento que pode resultar deste processo. A pesquisa pensada como experiência e como um gesto pedagógico (Massachelein, 2014) nos possibilita assumir o lugar instável e implicado da subjetividade do sujeito que pesquisa, e que, portanto, sabe que o trabalho da pesquisa é um experimento incompleto, muitas vezes rasurado pela falta de experiência de quem o 
produz. Mas o cuidado e atenção dada à densidade da experiência pode nos permitir que seja efetivado o processo de objetivação e reflexividade por meio do qual a experiência da pesquisa torna-se um campo de conhecimento e aprendizado.

Entendo que essas breves reflexões se tornam necessárias para pensar a experiência intergeracional como uma forma de se estar, olhar e conhecer a cidade com as crianças pequenas. Nesse sentido, pensando a experiência intergeracional e a questão da hospitalidade como possibilidade de ser vivida no aprendizado da cidade (Tavares, 2016), compreendo em diálogo com Walter Benjamin, que ler/aprender a cidade é antes de tudo um experimentum línguae (Agamben, 2005). Para Benjamin (1995), o contexto urbano é permeado de poéticas visuais, sonoras, textuais, alegorias que se apresentam como um texto coletivo; um livro de espaços aberto a possíveis leituras/escrituras que quando compartilhadas como experiências, vivências e modos de conhecimento, podem possibilitar os vínculos dos diferentes sujeitos com suas histórias e histórias da cidade.

Em nossos percursos de pesquisa com professoras(es) e crianças da Educação Infantil, narrar a megacidade polifônica, repleta de signos, nos coloca diante de algumas questões epistemológicas: a discussão da cidade, inicialmente associada aos seus aspectos físicos, territoriais recebe novos matizes quando associada à concepção de uma arquitetura porosa como uma rocha, na quais as construções e as ações das pessoas se entrelaçam umas nas outras, em diferentes circuitos da cidade. Nesse sentido, trazendo o diálogo com Benjamin (1995) e com a sua concepção da porosidade, a cidade é fundamentalmente algo indefinido, pronto e acabado. Como um livro de espaços, as formas da cidade ganham novas formas a partir do dinamismo da vida e dos percursos das diferentes pessoas na cidade.

A cidade de Paris, por exemplo, é vista pelo filósofo como um enorme livro a ser lido- "Paris é um grande salão de biblioteca atravessado pelo Sena" (Benjamin, 1995, p. 195). O olhar Benjaminiano flana por ruas e adentra monumentos e toda uma arquitetura grandiosa para nos mostrar um mundo decadente, mas apaixonadamente vivo e repleto de experiências pessoais: "Saber orientar-se numa cidade", afirma Benjamin (2000, p. 73)., "não significa muito. No entanto, perder-se numa cidade, como alguém que se perde numa floresta requer instrução". 
Trazendo essas questões para a metrópole contemporânea, palco e contexto de nossas pesquisas interessadas é fundamental discutir a questão do olhar, tendo em vista a questão de pensar a cidade de São Gonçalo como um (con) texto alfabetizador, reafirmando a nossa concepção da cidade como um livro de espaços, que para ser lido e compreendido, careceria de ser discutido/pensado também na escola da pequena infância:

Me ajuda a olhar! [...] Diego Não conhecia o mar. O pai, Santiago Kovadloff, levou-o para que descobrisse o mar. Viajara para o sul. Ele, o mar, estava do outro lado das dunas altas, esperando. Quando o menino e o pai enfim, alcançaram aquelas alturas de areia, depois de muito caminhar, o mar estava na frente de seus olhos. E foi tanta a imensidão do mar, e tanto o seu fulgor, que o menino ficou mudo de beleza. E quando, finalmente, conseguiu falar, tremendo, gaguejando, pediu ao pai: - Me ajuda a olhar! (Galeano, 1991, p. 15).

$\mathrm{O}$ pedido do menino Diego nos possibilita pensar que, dentre as inúmeras aprendizagens que construímos na vida, também podemos incluir a aprendizagem do olhar. Do olhar a cidade. Igualmente importante é retomar a epígrafe da contracapa do livro "Ensaio sobre a Cegueira" (1995) de José Saramago: "se olha, vê e se vê, repara". Reparar. Quase sempre o que não fazemos na cidade é reparar: re-parar. É necessário reparar a cidade, aprender a olhá-la. Discutir uma epistemologia do olhar com às crianças pequenas (Tavares, 2016).

Com Galeano e Saramago, pergunto: como podemos como pesquisadoras ajudar as crianças a olhar a cidade? Como podemos ensinar a cidade como um (con) texto alfabetizador? Como compreender o olhar das crianças sobre a cidade? Como tomar a cidade como um problema político e epistemológico?

Estas são algumas das questões que nos (co) movem a pensar a cidade como uma questão fundamental para os sujeitos escolares, em especial, às crianças da Educação Infantil, entendendo que a experiência urbana pode constituir um pano de fundo comum para experiências mais amplas, vinculadas ao compartilhamento do sensível, daquilo que nos afeta e nos torna (con) viventes na cidade. Nestes termos, as palavras de Walter Benjamin parecem ecoar em nossos ouvidos como um mantra delicado:

A força da estrada do campo é uma se alguém anda por ela, outra se a sobrevoa de aeroplano. Assim é também a força de um texto, uma se alguém a lê, outra se o transcreve. Quem voa, vê apenas como a estrada se insinua através da paisagem, e para ele, ela se desenrola segundo as mesmas leis que o terreno em torno. Somente quem anda pela estrada experimenta algo de seu domínio e de 
como, daquela mesma região que, para o que voa, é apenas a planície desenrolada, ela faz sair, a seu comando, a cada uma de suas voltas, distância, belvederes, clareiras, perspectivas, assim como o chamado do comandante faz sair soldados de uma fila. (Benjamin, 2000, P.16).

Para Benjamin (1994, p. 203), “a cidade é a realização do antigo sonho humano do labirinto". Na leitura de Olgária Matos, filósofa e leitora de Benjamin, “À cidade do absolutamente visível- racionalista e abstrata- se contrapõe a cidade infantil e alegórica, a cidade labiríntica com a qual a criança estabelece pactos secretos" (1989, p. 80). Para Benjamin, o labirinto não se reduz a uma estrutura onírica vertiginosa, ele é na sua essência o próprio avesso das obras culturais dos livros; são os subterrâneos das cidades.

Voltamos, desse modo, a perguntar: como tornar o direito à cidade uma experiência de felicidade, mesmo que clandestina? Como matricular as crianças na cidade, ganhando às ruas como numa manhã de domingo ensolarado? Com tornar a vida na metrópole contemporânea uma experiência de acolhimento e hospitalidade para as crianças pequenas, principalmente às crianças das classes populares (Tavares, 2003), que justamente por questões de classe, raça e gênero são as que mais se autorizam estar à deriva na cidade? “Quem caminha vive sempre uma experiência binária: de diferença e da igualdade, da individualidade e da sociabilidade, de si e do mundo" (Labbucci, 2013, p. 54).

Como já afirmado neste artigo, venho trabalhando com uma epistemologia polifônica que se fundamenta, principalmente, nos Estudos Sociais da Infância, buscando realizar pesquisas de inspiração etnográfica e colaborativa que tematizam a tríade escola da infância, o direito à cidade e alfabetização no sentido de leitura de mundo (FREIRE, 1979). Reitero que, do ponto de vista político e epistêmico, três horizontes de questões vêm embasando os meus itinerários de pesquisa:

A questão empírica: os componentes territoriais que constrangem ou possibilitam os processos de educabilidade das crianças das periferias urbanas gonçalenses. Os últimos dados do IBGE (2010) e da Secretaria Municipal de Educação de São Gonçalo (2016) parecem reiterar os dados empíricos coletados junto aos moradores entrevistados: vale dizer, não está ocorrendo à ampliação de vagas nas redes públicas de Educação Infantil, isto é, nas creches e pré-escolas 
municipais. A maioria dos moradores dos bairros periféricos só consegue vagas nas creches conveniadas, que funcionam precariamente à margem das políticas públicas municipais (Tavares, 2016).

A segunda questão ancora-se na questão dos direitos. Do ponto de vista do direito à cidade, das políticas urbanas e da urbanidade, amplia-se a pobreza, o desemprego e a precariedade urbana. Que reverberam no aumento da violência urbana. Morre-se e mata-se muito na cidade São Gonçalo, principalmente nos bairros e loteamentos irregulares, nas áreas pobres e periféricas da cidade.

Não há como deixar de relacionar essas questões aos processos de educabilidade das crianças pequenas das creches e escolas de Educação Infantil. São justamente elas, as crianças pequenas, que mais sofrem com a escalada da violência urbana em suas ruas e bairros, pois são alvos fáceis das "balas perdidas", tanto dos traficantes, quanto da própria polícia, pouco preparada para intervenção nessas áreas de conflitos. Escalada da violência esta, que dificulta, melhor dizendo, impede o direito à cidade, pois as crianças e suas famílias são impedidas de se deslocarem de suas casas, muitas vezes impedidas de saírem de casa (em direção à creche ou ao trabalho) após o "toque de recolher" dado pelos traficantes em confrontos sucessivos com a polícia local.

A terceira questão investigativa, diz respeito à questão política ao entender que, na contemporaneidade, vivemos um tempo político e institucional profundamente paradoxal, no qual a celebração formal dos procedimentos e virtudes democráticas, bem como a ampliação institucional dos espaços de participação e de fortalecimento da sociedade civil entram em choque com o crescente recrudescimento de uma "zona de indiferenciação entre o legal e o ilegal, o direito e o ilícito, entre o público e o privado, a norma e a exceção, produzindo uma inquietante linha de sombra na da vida urbana e suas formas políticas" (Tavares; Lucchesi, 2018, p. 28).

Ao investigar as trajetórias urbanas e os circuitos de educabilidade das crianças dos três bairros delimitados (Salgueiro, Jardim Catarina e Trindade) no trabalho de pesquisa, percebo a existência de uma zona de indeterminação que atravessa o emaranhado da vida social, repercutindo nas práticas e nos circuitos da 
vida urbana mais ampla, não somente nos equipamentos escolares, mas, sobretudo, nas práticas espaciais e nos deslocamentos cotidianos (ou na ausência deles) nesses bairros.

Do ponto de vista investigativo, entendo ser cada vez mais necessário aprofundar a concepção da pesquisa como uma experiência alteritária de conhecimento. Trata-se de focar e deslocar-se do campo do já sabido para a formulação de novas questões e novos problemas, num esforço de complexificar o olhar para o terreno movediço no qual a realidade-território se move/produz.

Assim, em meus estudos, venho aprofundando a concepção de que a cidade, mais do que um conceito, é um campo de práticas (Tavares; Lucchesi, 2018). Não se trata de inventar novas teorias e muito menos de domesticar a (s) realidade (s) estudada (s) em alguma matriz explicativa geral. Ao pensar a cidade como um campo de práticas, sobretudo de práticas infantis de conhecimento, representação e apropriação do espaço urbano, busca-se elaborar um plano de investigação mais flexível, mais aberto, que ao produzir linhas de força, continua a instigar a pensar de forma plural e inventiva a questão urbana, sobretudo em diálogo com os diferentes profissionais que trabalham nas escolas da pequena infância.

Esse horizonte para além de ser epistêmico, também é político, me inspirando à formulação de novas questões, novos problemas de análise, principalmente em diálogo com o mundo da escola da pequena infância que, raramente não tematiza a vida urbana como uma questão-limite para os processos de educabilidade infantil, especialmente por compreender que a "infância é o outro" (Larrosa, 1998, p.69), sendo ela constituída por crianças extremamente heterogêneas, inseridas num mundo de múltiplas diferenças e em uma relação de alteridade conosco:

\{...\}Isso é a experiência da criança como outro: o encontro com uma verdade que não aceita a medida de nosso saber, como uma demanda de iniciativa que não aceita a medida de nosso poder e com a exigência de hospitalidade que não aceita a medida de nossa casa (Larrosa,1998, p. 71).

Em minhas "alfabetizações cotidianas", venho aprendendo como pesquisadora que a temática dos direitos, dentre eles o direito à cidade, isto é, da criança conhecer e usufruir do 
seu território é uma questão estrutural, de longa duração que não pode ser visibilizada apenas pela escola da infância.

A cidadania existente entre nós é fruto de relações sociais complexas, conflitivas, construída em meio a combates e negociações. Nessa perspectiva, interrogar as virtualidades do lugar nos permite reconstruir a dialética do local como arena de antagonismos e complementaridades. Desse modo, tanto o governo municipal, quanto os movimentos sociais, e os espaços institucionalizados de participação e/ou representação na cidade, parecem intuir sobre as virtualidades do lugar como espaços de (re) existência e, também, como o conjunto de oportunidade para a disputa de outros projetos de vida urbana.

Essas questões ajudam a reiterar que, uma condição cidadã é uma aprendizagem cotidiana construída nas diferentes instâncias sociais da qual a escola da infância, por sua natureza histórica e social, representa uma dimensão política fundamental (Tavares, 2003).

Assim, a cidadania infantil e o próprio direito à cidade não podem ser tomados e investigados como um dado natural, mas como uma aprendizagem fundamentalmente social, podendo ser tornar nas instituições escolares um desafio pedagógico e cultural, enraizandose nas práticas cotidianas. Constituindo-se, portanto, em aprendizagens fortemente alicerçadas no encontro intergeracional, fundamentada nas trocas geracionais que aproximam (mas que também podem distanciar) adultos, jovens e crianças, como nos dois filmes de Hirokazu Korreda $(2004,2011)$ referenciados nesse artigo.

Desse modo, o que o trabalho meticuloso e dedicado da pesquisa vem possibilitando afirmar é a riqueza do cotidiano da escola da pequena infância para a educabilidade e a formação de uma "cultura de direitos" (Arendt, 1995) na qual adultos e crianças possam se reconhecer como sujeitos e co-construtores ativos de seus destinos no (s) mundo (s). Para finalizar, sempre cabem os versos do poeta Antonio Ramos Rosa (1989), para quem: Tudo já foi dito. Tudo está por dizer. Tudo está por dizer no que já foi dito.

Portanto, ainda urge dizer que é preciso apr(e)ender a cidade, perder-se e achar-se nela. Perguntar à cidade os seus segredos, as suas contradições. Ainda urge dizer que é preciso (re)aprender a cidade com os pequenos e a sua lentidão a olhar as coisas do mundo, aprendendo a enxergar e a reparar como os pequenos e os poetas fazem. Urge dizer que é preciso (re)aprender a força dos pequenos que ainda buscam os/as deuses/as no mundo, que ainda se perdem olhando as pedras portuguesa das calçadas e as nuvens no céu, que olham os telhados e se atrasam (Tavares, 2003). Porque (sem inocência) ainda buscam o 
extraordinário e o encantamento do mundo. Talvez na cidade, talvez na escola. Quiçá em ambas.

\section{referências}

Agamben, G. Infância e História: destruição da experiência e origem da história. Belo Horizonte: UFMG, 2005.

Andrade, C.D. de. O Outro. IN: Poesia e Prosa. Rio de Janeiro: Nova Aguillar, 1979.

Arendt, H. A Condição Humana. São Paulo: Forense Universitária, 1995.

Arendt, H. Reflexões sobre Little Rock. In: Arendt, H. Responsabilidade e Julgamento. 1. ed. São Paulo: Companhia das Letras, 1959. p. 261-281.

Arendt, H. A crise na educação. In: Between past and future: six exercises in political thought, Nova York, 1961. 173-196. Disponível em:

<http://www.gestaoescolar.diaadia.pr.gov.br/arquivos/File/otp/hanna_arendt_ crise_educacao.pdf $>$.Acesso em: 22 de janeiro de 2020.

Benjamin, W. Infância em Berlim. In: Obras escolhidas II: Rua de Mão Única. São Paulo: Brasiliense, 2000.

Benjamin, W. Charles Baudelaire- um lírico no auge do capitalismo. Obras escolhidas III. São Paulo: Brasiliense, 1995.

Castro, L. R. Subjetividade e Cidadania: um estudo com crianças e jovens em três cidades brasileiras. Rio de janeiro: Sete Letras, 2001.

Castro, L. R. O Futuro da Infância: e outros escritos. Rio de Janeiro: Sete Letras/FAPERJ, 2013.

Collins, P. H. Pensamento Feminista Negro. (J. P. Dias, Trad.). São Paulo: Boitempo, 2019.

Corsaro, W. "Reprodução Interpretativa e Cultura de pares". In: Muller, F. \& Carvalho, A. M. (Orgs.). Teoria e Prática na pesquisa com crianças: diálogos com William Corsaro. São Paulo: Cortez, 2009.

Derrida, J.; Dufoumantelle, A. Da Hospitalidade. (A. Romane, Trad.). São Paulo: Escuta,2003.

Faria, A.L. G.; Finco, D. (Orgs.). Sociologia da infância no Brasil. Campinas: Autores Associados, 2011.

Farias, A. B. de. Poéticas da Hospitalidade: Ensaios para uma filosofia do acolhimento. Porto Alegre: Zouk, 2018.

Freinet, C. Para uma escola do povo: guia prático para a organização material, técnica e pedagógica da escola popular. Lisboa: Presença, 1973.

Freire, P. Pedagogia do oprimido. Rio de Janeiro: Paz e Terra, 1979.

Freire, P. A importância do Ato de Ler: em três artigos que se completam. São Paulo: Cortez, 1986.

Freire, P. \& Macedo, D. Alfabetização: leitura do mundo, leitura da palavra. São Paulo: Paz e Terra, 1990.

Freire, P. Pedagogia da Esperança. São Paulo: Paz e Terra, 1993.

Galeano, E. O Livro dos Abraços. $2^{\text {a }}$ Edição. Porto Alegre: L\&PM, 2008.

Labbucci, A. Caminhar, uma revolução. São Paulo: Martins Fontes, 2013.

Larrosa, J. O enigma da infância ou o que vai de impossível ao verdadeiro. In: Larrosa, J.; Lara, N, P. (orgs.). Imagens do Outro. Petrópolis: Vozes, 1998.

Lefebvre, H. O Direito à Cidade. São Paulo: Editora Moraes, 1991.

Matos, O.C.F. Benjaminianas: Cultura capitalista e Fetichismo contemporâneo. São Paulo: Editora UNESP, 2010. 
Masschelein, J. O mundo "mais uma vez": andando sobre linhas. IN: Martins, F.F.R.; Netto, M.J.V.; Kohan, W. O. (orgs.). Encontrar Escola. Rio de Janeiro: Lamparina/FAPERJ, 2014.

Santos, B. S. A Crítica da Razão Indolente. Contra o desperdício da experiência. Porto: Afrontamentos, 2000.

Santos, M. Técnica espaço tempo: globalização e meio técnico-científico informacional. São Paulo: Hucitec, 1997.

Santos, M. O Espaço do cidadão. São Paulo: Nobel, 1996.

Saramago, J. Ensaio sobre a Cegueira. São Paulo: Companhia das Letras, 1995.

Sarmento, M.J. \& Gouvea, M.C.S. (orgs.). Estudos da infância: educação e práticas sociais. Petrópolis: Vozes, 2008.

Tavares, M.T.G. A Infância e a Cidade: investigando componentes territoriais de processos formativos de crianças na cidade de São Gonçalo. Projeto de Pesquisa Prociência -UERJ/FAPERJ, Rio de Janeiro, 2016.

Tavares, M.T.G. A(s) Infância(s) e a cidade: discutindo processos formativos de crianças nos territórios gonçalenses. Projeto de Iniciação Científica, UERJ, Rio de Janeiro, 2010.

Tavares, M.T.G. Os "pequenos", a Escola da Infância e o Direito à cidade. IN: Lopes, J.J.M.; Mello, M. B. de. "O Jeito de que nós crianças pensamos sobre certas coisas": Dialogando com lógicas infantis. Rio de Janeiro: Rovelle, 2009.

Tavares M.T.G. Os Pequenos e a cidade: O papel da Escola na construção de uma alfabetização cidadã. 203 f. Tese (Doutorado em Educação) - Universidade Federal do Rio de Janeiro, Rio de Janeiro, 2003.

T984022, M.T.G.; LucchesI, J. C. A cidade como um livro de espaços: lendo e pensando a cidade com a(s) infâncias(s)de creches comunitárias do Rio de Janeiro. In: Carreiro, H.J.S.; Tavares, M.T. G.(orgs.). Estudos e Pesquisas com o Cotidiano da Educação das Infâncias de Periferias Urbanas. São Carlos: Pedro \& João Editores, 2018.

recebido em: 28.01 .2020

aprovado em: 08.06.2020 